\title{
Change in patients' body weight after 12 months of treatment with glimepiride or glibenclamide in Type 2 diabetes: a multicentre retrolective cohort study
}

\author{
S. Martin ${ }^{1}$, H. Kolb ${ }^{1}$, J. Beuth ${ }^{2}$, R. van Leendert ${ }^{2}$, B. Schneider ${ }^{3}$, W. A. Scherbaum ${ }^{1}$ \\ ${ }^{1}$ Clinical Department, German Diabetes Centre at the Heinrich-Heine University, Düsseldorf, Germany \\ ${ }^{2}$ Institute for Scientific Evaluation of Naturopathy, University of Cologne, Germany \\ ${ }^{3}$ Institute of Biometry, Medizinische Hochschule, Hanover, Germany
}

\section{Abstract}

Aims/hypothesis. Our study compared the effects of glimepiride or glibenclamide treatment on body weight over 12 months of treatment in patients with Type 2 diabetes in routine outpatient practice.

Methods. This new retrospective study design used data from physicians in a restricted manner (retrolective). Data from case report forms from 520 patients from 91 randomly selected centres were assessed and covariance analysis performed.

Results. The influence of practice and patient characteristics on treatment assignment was low, reflecting the design of randomised controlled trials. Mean weight loss and reduction in body mass index from baseline to study endpoint were greater with glimepiride than with glibenclamide $(-2.04 \pm 3.99 \mathrm{~kg}$ vs $-0.58 \pm 3.65 \mathrm{~kg}, \quad p<0.001 ; \quad-0.71 \pm 1.38 \mathrm{~kg} / \mathrm{m}^{2} \quad \mathrm{vs}$ $\left.-0.20 \pm 1.28 \mathrm{~kg} / \mathrm{m}^{2}, p<0.001\right)$. Duration of treatment at baseline influenced treatment outcome, but propensi- ty score, sex, age and fasting blood glucose at baseline did not. Both glimepiride and glibenclamide led to decreases in fasting blood glucose $(-2.43 \pm$ $0.24 \mathrm{mmol} / \mathrm{l}$ vs $-3.03 \pm 0.24 \mathrm{mmol} / \mathrm{l} ; p<0.001$ vs baseline) and $\mathrm{HbA}_{1 \mathrm{c}}(-1.23 \pm 0.09 \%$ vs $-1.26 \pm 0.09 \%$; $p<0.001$ vs baseline). Both treatments were associated with a decrease in serum total cholesterol and low density lipoprotein cholesterol. Triglycerides were lower in the glibenclamide group and high density lipoprotein cholesterol was higher in the glimepiride group only.

Conclusions/interpretation. Initial treatment of Type 2 diabetes with glimepiride was associated with a significantly greater decrease in body weight and body mass index than treatment with glibenclamide, while providing equivalent glycaemic control. [Diabetologia (2003) 46:1611-1617]

Keywords Body mass index, glimepiride, glibenclamide, retrolective, Type 2 diabetes.
Up to $90 \%$ of patients diagnosed with Type 2 diabetes are overweight [1]. In these patients weight loss is associated with a considerable improvement in metabolic and clinical factors, including $\mathrm{HbA}_{1 \mathrm{c}}$, fasting plasma glucose, triglyceride concentrations and insulin

Received: 23 June 2003 / Revised: 8 August 2003

Published online: 5 November 2003

C) Springer-Verlag 2003

Corresponding author: Dr. S. Martin, Clinical Department, German Diabetes Centre at the Heinrich-Heine University, Auf'm Hennekamp 65, 40225 Düsseldorf, Germany

E-mail: martin@ddfi.uni-duesseldorf.de

Abbreviations: FBG, Fasting blood glucose; SU, sulphonylurea; UKPDS, United Kingdom Prospective Diabetes Study. sensitivity [2]. Although diet and exercise are recommended as an initial therapy for newly diagnosed Type 2 diabetic patients, drug therapy begins in most patients at least 3 months after diagnosis [3]. Weight gain is considered to be a disadvantage of sulphonylurea (SU) therapy; however, previous studies suggest that glimepiride has a weight-neutral effect on patients with Type 2 diabetes $[4,5]$. Despite its importance, change in body weight has never been taken as the primary endpoint in any prospective or retrospective clinical studies with oral antidiabetic drugs.

Glimepiride is a once-daily SU, which differs from older agents in this class, e.g. glibenclamide, in that it is associated with equivalent metabolic control with lower stimulation of insulin secretion [6,7], and with 
a lower incidence of hypoglycaemia [8]. Glimepiride has been shown to increase first- and second-phase insulin secretion [9], whereas glibenclamide only affects the second phase. Glimepiride also exerts various extrapancreatic, insulin-independent, glucose-lowering effects, and has been shown to improve peripheral glucose uptake and reduce endogenous glucose production [10].

Retrospective, observational studies have previously been perceived to produce less reliable results than prospective, experimental studies, as they can potentially overestimate treatment effects through, for example, use of historical controls or non-randomisation $[11,12]$. Recent evidence, however, has indicated that well-designed observational cohort studies do not systematically overestimate or underestimate the effect of treatment compared with randomised controlled trials investigating the same clinical topic $[13,14]$, provided that a number of criteria similar to those in a randomised trial are fulfilled [15].

Retrolective observational cohort studies are population (epidemiologic) studies based on a representative sample of patients treated routinely in clinics or general practices, with rigid inclusion and exclusion criteria and treatment allocation prior to study initiation enabling valid comparisons of the safety and efficacy of treatments. The dependence on baseline conditions and other characteristics can be quantified by the propensity score, a proven tool for making adjustments for preferences and characteristics $[16,17$, 18]. Retrolective observational cohort studies allow us to assess whether the beneficial effects of therapeutic treatments observed in controlled, prospective clinical trials occur in daily clinical practice, thereby providing valuable information on the effectiveness and safety of such treatments in broad patient populations.

Our study used the retrolective observational cohort study design to compare retrospectively the effect on body weight of treatment with glimepiride or glibenclamide over a 12-month period in patients with Type 2 diabetes in routine clinical practice.

\section{Subjects and methods}

Study design. This was a multicentre, observational study with a controlled retrolective cohort study design in newly diagnosed Type 2 diabetic patients from 91 practices in Germany.

Investigation sites. Practices were chosen at random from a comprehensive public address database of doctors' practices (Pan-Adress, Munich, Germany), while maintaining a ratio between specialised and other practices. The practices included were general practitioners, diabetologists and internists, and were representative of practices where Type 2 diabetes is diagnosed and the initial dose adjustment of medication (including insulin) is carried out. The number of patients recruited was proportional to the total number of patients with Type 2 diabetes treated at the practice during the observation period.
Subjects. Drug treatment-naïve patients with a confirmed diagnosis of Type 2 diabetes who, with or without dieting, received an initial dose adjustment with glimepiride or glibenclamide during the period from April 1998 to March 1999 were included in the study. Additional inclusion criteria were: age 35 years or older, disease duration less than 5 years, BMI $27 \mathrm{~kg} / \mathrm{m}^{2}$ or higher. Patients who, before or during the study, were taking any antidiabetic drugs other than glimepiride or glibenclamide or any medication known to influence body weight were excluded. During the observation period it was required that a consistent method of measuring body weight was adopted for each patient. However, as the aim of the study was to assess weight differences, the method of weight measurement did not have to be identical in all practices. Documentation of body weight, fasting blood glucose (FBG), systolic and diastolic blood pressure and $\mathrm{HbA}_{1 \mathrm{c}}$ values were needed for a 12-month period after initial dose adjustment.

Study protocol. The study comprised two visits by the patients, one at the start of treatment, the other after 1 year ( \pm 3 months). Weight measurement procedures were the same at both visits; patients were measured on the same scales, and control measurements were taken to assess accuracy. Patient details were transferred to case report forms, and strict standard operating procedures and close monitoring of data acquisition were implemented to ensure good data quality. Patient and physician characteristics were recorded. Independent monitors verified the accuracy of the data by a special interview technique. Interviews were conducted together with the physicians.

Study outcomes. The primary outcomes assessed were mean change in body weight and BMI after 12 months of treatment. The secondary outcomes were changes in diabetes-related variables $\left(\mathrm{HbA}_{1 \mathrm{c}}\right.$, FBG, cholesterol).

Statistical analysis. It was estimated that a sample size of 500 patients was required to show a significant difference between groups in mean change in body weight at the $5 \%$ level and with a power of $90 \%$, providing that the true difference of the expectations in the population is at least 0.3 -fold that of the standard deviation. This estimate assumed a standard deviation of $4 \mathrm{~kg}$ for a true mean difference of $1.2 \mathrm{~kg}$ in body weight between treatment groups.

The per protocol population (patients who met all inclusion criteria and none of the exclusion criteria) was used for all analyses. The propensity score was estimated by logistic regression from the cohort data, with physician and patient characteristics taken into consideration as covariables that could have influenced treatment assignment.

For the primary outcome of change in body weight or BMI, unadjusted mean changes were compared for independent samples using a Student's $t$ test. Analysis of covariance was used to analyse the influence of the propensity score and baseline characteristics on the change in weight or BMI, and to test the difference in adjusted changes between treatment groups. Adjusted changes in body weight and BMI were evaluated with the estimated linear regression function with the mean values of the covariates listed. For each treatment group, the mean, standard error and $95 \%$ CI of the adjusted changes in weight and BMI were calculated and tested between the groups using an $F$ test. Statistical analysis was done with SPSS+ for Windows, version 11 .

Changes in diabetes-related variables $\left(\mathrm{HbA}_{1 \mathrm{c}}\right.$, FBG, cholesterol) during the treatment period were compared between treatment groups using the Wilcoxon's sign-rank test. Differences in laboratory variables between treatment groups at baseline and endpoint were assessed using the Mann-Whitney test. 
Table 1. Baseline characteristics and data of study patients

\begin{tabular}{|c|c|c|c|c|c|}
\hline \multirow{2}{*}{$\begin{array}{l}\text { Treatment } \\
\text { Variable }\end{array}$} & \multicolumn{2}{|l|}{ Glimepiride } & \multicolumn{2}{|c|}{ Glibenclamide } & \multirow[t]{2}{*}{$p$ value } \\
\hline & Mean \pm SD & $n$ & Mean \pm SD & $n$ & \\
\hline Body weight (kg) & $87.56 \pm 12.94$ & 251 & $86.84 \pm 12.55$ & 269 & 0.518 \\
\hline BMI $\left(\mathrm{kg} / \mathrm{m}^{2}\right)$ & $30.60 \pm 3.17$ & 251 & $30.41 \pm 3.27$ & 269 & 0.502 \\
\hline $\mathrm{HbA}_{1 \mathrm{c}}(\%)$ & $8.12 \pm 1.54$ & 247 & $8.32 \pm 1.56$ & 254 & 0.154 \\
\hline
\end{tabular}

Table 2. Baseline characteristics and data of study physicians

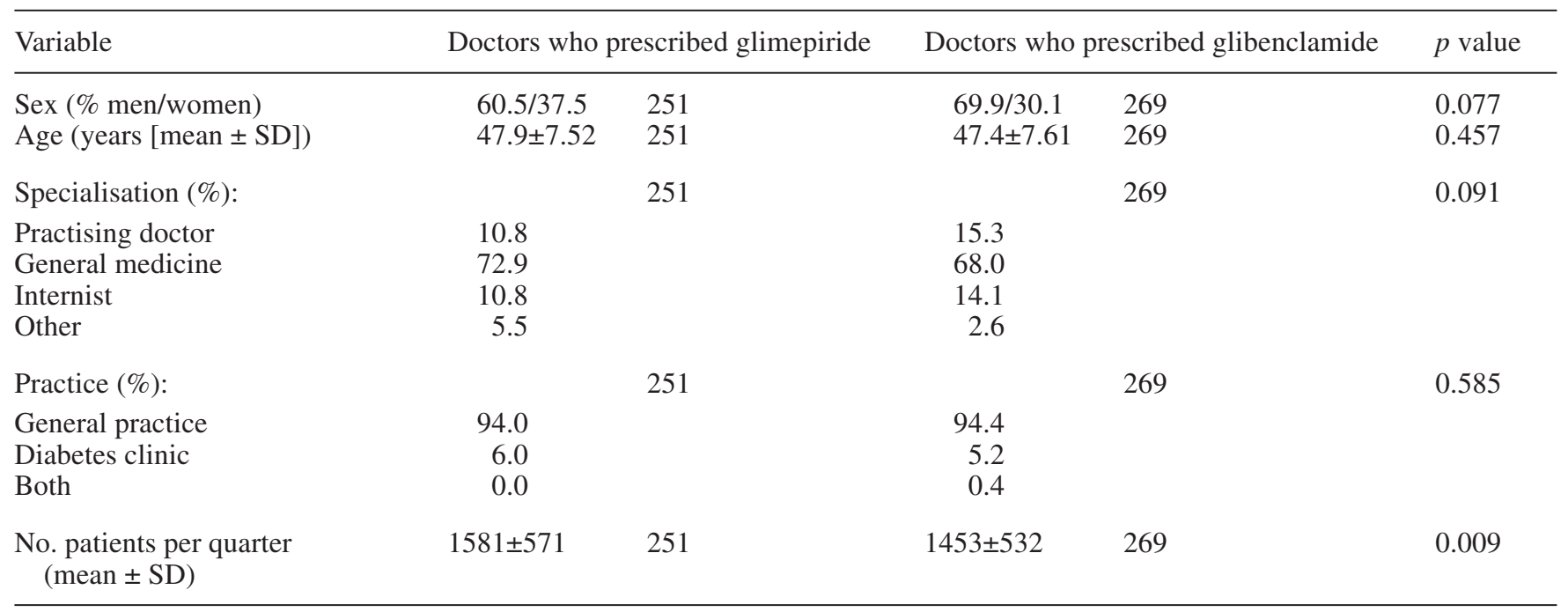

FBG, fasting blood glucose

\section{Results}

Study population. Details of 802 patients from 91 practices were documented. Of these, 520 patients were eligible for the per protocol population, 251 of whom were receiving glimepiride (glibenclamide: 269). The reasons for excluding the 282 patients were: missing or unclear data on initial treatment $(n=36)$, first visit outside the investigation period $(n=76)$, interval between first and second visit less than 270 or more than 600 days $(n=35)$, BMI at first visit below $27 \mathrm{~kg} / \mathrm{m}^{2}(n=134)$, and missing blood pressure values $(n=1)$.

The mean time interval between first and second visits was 389 days for glimepiride and 390 days for glibenclamide $(p=0.830)$. The mean daily doses increased in this period of time for both treatment groups (glimepiride: $2.02 \mathrm{mg}$ to $2.42 \mathrm{mg}$ ); glibenclamide: $4.95 \mathrm{mg}$ to $6.17 \mathrm{mg})(p<0.001)$.

The baseline characteristics and patient data of the two patient groups were generally similar, though small but statistically significant differences were noted for age $(p=0.005)$ and FBG $(p=0.023)$ (Table 1). The baseline data of the physicians and practices where patients were treated were similar for both treatment groups. However, physicians who prescribed glimepiride treated significantly more patients per quarter $(p=0.009)$ and were more likely to be women than those prescribing glibenclamide $(p=0.077)$ (Table 2).

Study outcomes: Body weight and BMI. Both treatments led to significant reductions in body weight and BMI over the observed treatment period $(p<0.001)$. Mean weight loss from baseline to study endpoint was greater with glimepiride than with glibenclamide $(-2.04 \pm 3.99 \mathrm{~kg}$ vs $-0.58 \pm 3.65 \mathrm{~kg} ; p<0.001$, Fig. 1a). Although the variability of the changes between centres was significant $(p<0.001)$, the differences between treatment arms in change in body weight from baseline remained significant $(p=0.027)$ if the centres were taken into account as an additional factor. Accordingly, glimepiride achieved a larger reduction in BMI than glibenclamide over the observed period $\left(-0.71 \pm 1.38 \mathrm{~kg} / \mathrm{m}^{2}\right.$ vs $\left.-0.20 \pm 1.28 \mathrm{~kg} / \mathrm{m}^{2} ; p<0.001\right)$ (Fig. 1b). Interestingly, identical results for body weight were obtained from analysis of the full data set compared with the per protocol data set, showing that 
a

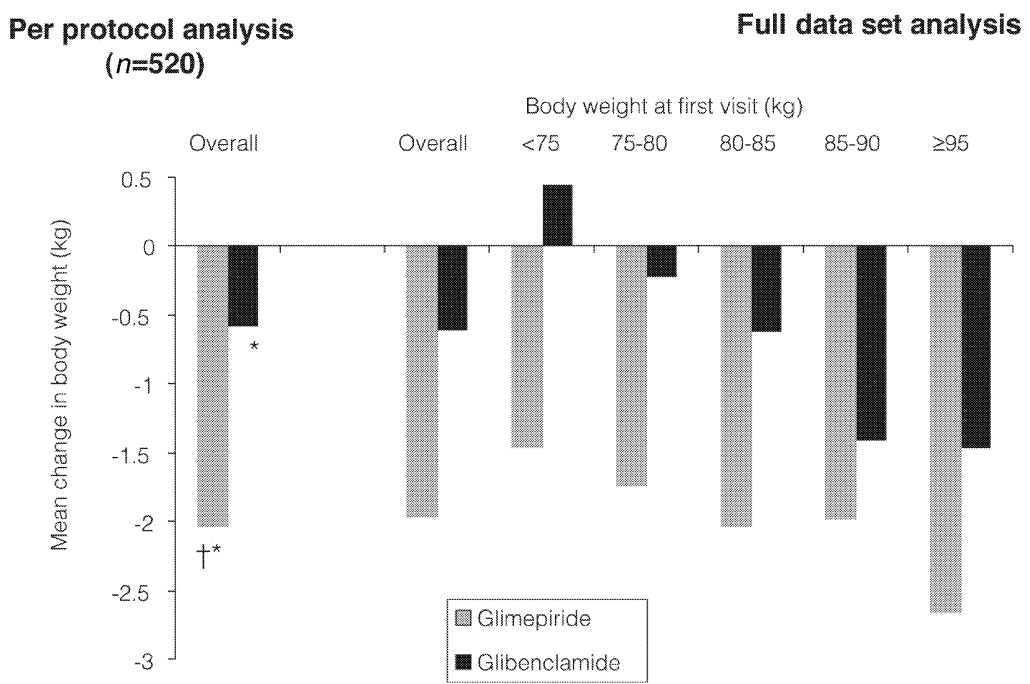

b

Per protocol

analysis $(n=520)$

Full data set analysis $(n=766)$

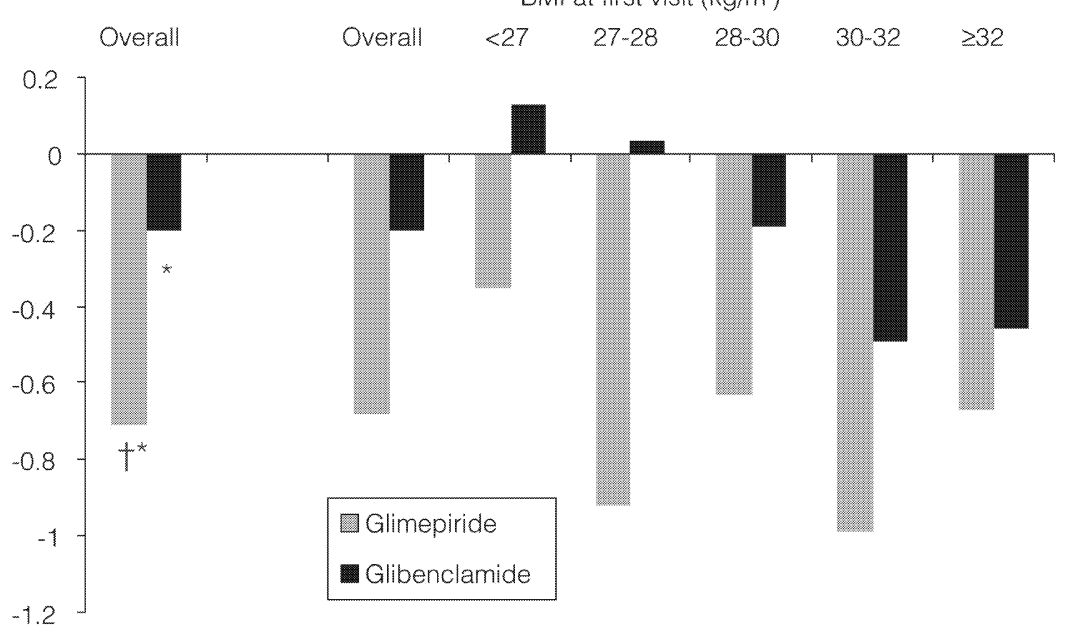

Fig. 1a, b. Effect of 12 months of treatment with glimepiride or glibenclamide on (a) body weight and (b) BMI and the dependence of these changes from baseline on baseline values. ${ }^{*} p<0.001$ vs baseline; $\uparrow p<0.001$ vs glibenclamide

the larger reduction achieved by glimepiride is also true for patients with acceptable or mildly too high body weight. For the full data set, an increase in BMI under SU therapy was only seen in patients with a BMI below $28 \mathrm{~kg} / \mathrm{m}^{2}$ and receiving glibenclamide. An increase in body weight was seen only with glibenclamide treatment in patients with a body weight below $75 \mathrm{~kg}$ at baseline (Fig. 1).

Influence of variables on the difference in mean body weight and BMI change. Covariance analysis showed that propensity score, sex, age and FBG at baseline had no significant influence on change in body weight. Body weight at first visit had an influence on

change in body weight ( $p=0.064)$, and the duration of treatment at baseline significantly influenced treatment outcome $(p=0.002)$. The adjusted mean change in body weight from baseline in glimepiride-treated patients $(-2.01 \mathrm{~kg})$ was greater than in patients treated with glibenclamide $(-0.63 \mathrm{~kg} ; p<0.001)$. Moreover, these adjusted changes were similar to unadjusted changes from baseline $(-2.04 \mathrm{~kg}$ and $-0.58 \mathrm{~kg}$ for glimepiride and glibenclamide respectively).

Similar results were obtained for the covariance analysis of change in BMI. The propensity score, sex, age, baseline FBG and baseline BMI had no significant influence on treatment outcome. Treatment duration at baseline had a significant influence on change in BMI $(p=0.002)$. The adjusted mean changes in BMI from baseline for patients treated with glimepiride and glibenclamide $\left(-0.705 \mathrm{~kg} / \mathrm{m}^{2} \mathrm{vs}-0.215 \mathrm{~kg} / \mathrm{m}^{2}\right)$ were similar to the unadjusted changes $\left(-0.71 \mathrm{~kg} / \mathrm{m}^{2} \mathrm{vs}-0.20 \mathrm{~kg} / \mathrm{m}^{2}\right)$.

Diabetes-related laboratory variables. There were significant decreases from baseline $(p<0.001)$ in FBG and 
Table 3. Change in laboratory results after sulphonylurea treatment

\begin{tabular}{|c|c|c|c|c|c|c|}
\hline \multirow{2}{*}{$\begin{array}{l}\text { Treatment } \\
\text { Change }\end{array}$} & \multicolumn{3}{|l|}{ Glimepiride } & \multicolumn{3}{|l|}{ Glibenclamide } \\
\hline & Mean change \pm SEM & $n$ & $p$ value & Mean change \pm SEM & $n$ & $p$ value \\
\hline In $\mathrm{HbA}_{1 \mathrm{c}}(\%)$ & $-1.23 \pm 0.09$ & 245 & $<0.001$ & $-1.26 \pm 0.09$ & 253 & $<0.001$ \\
\hline In total cholesterol (mmol/l) & $-0.31 \pm 0.06$ & 233 & $<0.001$ & $-0.29 \pm 0.06$ & 251 & $<0.001$ \\
\hline In HDL cholesterol (mmol/l) & $0.07 \pm 0.02$ & 126 & 0.004 & $-0.02 \pm 0.04$ & 128 & 0.924 \\
\hline
\end{tabular}

FBG, fasting blood glucose

$\mathrm{HbA}_{1 \mathrm{c}}$ values with glimepiride and with glibenclamide (FBG: $-2.43 \pm 0.24 \mathrm{mmol} / \mathrm{l}$ vs $-3.03 \pm 0.24 \mathrm{mmol} / \mathrm{l}$; $\mathrm{HbA}_{1 \mathrm{c}}:-1.23 \pm 0.09 \%$ vs $-1.26 \pm 0.09 \%$; Table 2). Decreases from baseline were also seen with glimepiride and with glibenclamide for total cholesterol $(-0.31 \pm 0.06 \mathrm{mmol} / \mathrm{l}$ vs $-0.29 \pm 0.06 \mathrm{mmol} / \mathrm{l} ; p<0.001$ vs baseline) and LDL cholesterol $[-0.21 \pm 0.06 \mathrm{mmol} / 1$ $(p=0.001)$ vs $-0.33 \pm 0.07 \mathrm{mmol} / 1 \quad(p<0.001)]$. High density lipoprotein cholesterol only increased in the glimepiride group, with changes from baseline of $+0.07 \pm 0.02 \mathrm{mmol} / \mathrm{l}(p=0.004)$ and $-0.02 \pm 0.04 \mathrm{mmol} / \mathrm{l}$ $(p=0.924)$ for glimepiride and glibenclamide respectively. Triglyceride values only decreased in the glibenclamide group, with changes from baseline of $-0.03 \pm 0.12 \mathrm{mmol} / \mathrm{l}(p=0.111)$ and $-0.29 \pm 0.09 \mathrm{mmol} / \mathrm{l}$ $(p<0.001)$ for glimepiride and glibenclamide respectively (Table 3 ).

Please note that as this study was done retrospectively in routine clinical practice, no conclusions on safety can be made.

Dependence of treatment assignment on baseline characteristics. The propensity score was used to assess the correlation between treatment assignment and physician and patient baseline characteristics. The probability of being prescribed glimepiride was greater with female physicians (odds ratio $2.129 ; 95 \%$ CI 1.281 to $3.583 ; p=0.004$ ) or older physicians (odds ratio 1.046; $95 \%$ CI 1.015 to $1.078 ; p=0.004$ ) and in practices with a higher number of patients per quarter (odds ratio $2.086 ; 95 \%$ CI 1.344 to $3.237 ; p=0.001$ ). It was lower in practices with a higher percentage of patients treated exclusively by dieting (odds ratio $0.954 ; 95 \%$ CI 0.925 to $0.984 ; p=0.003$ ). Moreover, the probability of being prescribed glimepiride was lower in older patients (odds ratio $0.978 ; 95 \%$ CI 0.959 to $0.998 ; p=0.031$ ) or patients with a higher initial FBG (odds ratio 0.997; $95 \%$ CI 0.993 to $1.000 ; p=0.054)$. Overall, the influence of practice and patient characteristics on the prescription of glimepiride was low, so treatment assignment can be considered almost independent of these characteristics, as in controlled randomised trials.

In a separate questionnaire completed by all physicians, the educational programme and recommenda- tions for diet were assessed in each participating centre. Analysis of this data showed that differences between the glimepiride and glibenclamide treatment groups in terms of diet recommendations were negligible, suggesting that variations in diet did not contribute to the differences in weight changes between treatment groups.

\section{Discussion}

This retrolective, observational cohort study shows that initial therapy with glimepiride leads to greater reductions from baseline in body weight and BMI than treatment with glibenclamide in patients with newly diagnosed Type 2 diabetes in clinical practice. Both treatments enabled effective glycaemic control, as measured by $\mathrm{HbA}_{1 \mathrm{c}}$ and $\mathrm{FBG}$ concentrations, in agreement with previous studies [19]. As expected, both also reduced serum total cholesterol and LDL cholesterol, with an increase in HDL cholesterol seen only in the glimepiride group.

A major limitation of many agents used to achieve glycaemic control is that they promote weight gain. The results from this study are in accordance with previous trials showing that treatment with glimepiride results in greater weight loss than treatment with other SUs $[4,5]$. Previous observational cohort studies have shown considerable weight losses with glimepiride. In a study of patients with BMI higher than $30 \mathrm{~kg} / \mathrm{m}^{2}$, treatment with glimepiride led to weight loss of up to $2.2 \mathrm{~kg}$ within 8 weeks [4]. In a second study, average weight losses of $3.0 \mathrm{~kg}$ were reported after 1.5 years of glimepiride treatment [5].

Among prospective studies investigating the effect of oral antidiabetic agents on weight change, the United Kingdom Prospective Diabetes Study (UKPDS) is to date the only one to report weight gain associated with glibenclamide (average gain: up to $5 \mathrm{~kg}$ over 10 years) [3]. The UKPDS studied patients with BMI below $27 \mathrm{~kg} / \mathrm{m}^{2}$, which is not representative of patients with Type 2 diabetes. Our study included only patients with a BMI at baseline of $27 \mathrm{~kg} / \mathrm{m}^{2}$ or more, and therefore had a clinically more realistic patient popu- 
lation. Moreover, the full data set analysis also includes patients with BMI lower than $27 \mathrm{~kg} / \mathrm{m}^{2}$. Patients receiving glibenclamide had increased BMI at study endpoint, which is consistent with the findings of the UKPDS [3]. In contrast, reductions in BMI and body weight were seen with glimepiride and glibenclamide for all other baseline categories of body weight and BMI.

The mechanism behind the weight loss associated with glimepiride has not been established. However, it is likely that the lower insulin secretion stimulated by glimepiride relative to other SUs is involved [6, $7,19,20]$. Acute post-challenge hyperinsulinaemia predicts weight gain [21], and an intervention study in normoglycaemic, morbidly obese adolescents showed that metformin treatment led to greater weight loss than placebo [22]. Moreover, glimepiride also exerts a number of extrapancreatic, insulin-independent, glucose-lowering effects $[6,7,20]$, and improved peripheral glucose uptake and decreased endogenous glucose production have both been observed after treatment with glimepiride [10]. These insulin-sparing effects of glimepiride could, therefore, explain the weight neutrality or weight loss associated with its use. Interestingly, the metabolites both of glimepiride and glibenclamide have been shown to have hypoglycaemic activity [23, 24], so it is unlikely that differences in metabolite activity explain the different effects on weight change reported here.

Fear of biased results has often been associated with observational studies. However, recent evidence suggests that observational, retrospective trials can provide valid results that do not overestimate the treatment effect. In an evaluation of 53 observational studies and 83 randomised, controlled trials of 19 treatment comparisons, only two of the 19 analyses showed that the combined magnitude of the effect in observational studies lay outside the $95 \%$ confidence limits of the randomised, controlled trials [13]. Similarly, another study showed clear similarities between the findings of total observational studies and randomised, controlled trials upon analysis of 99 trials investigating five clinical topics [14]. The results of our study closely mirror the findings of previous prospective trials investigating the efficacy of SUs, indicating that the retrolective study design allows reliable investigation of the long-term therapeutic value of drugs in a routine clinical setting.

In conclusion, this study again demonstrates the validity of the retrolective study design, and provides further evidence for the therapeutic value of glimepiride in clinical practice. Under the present conditions of Type 2 diabetes management in Germany, the initial treatment of the disease with glimepiride has been associated with a greater decrease in body weight and BMI than treatment with glibenclamide, while providing equivalent glycaemic control.
Acknowledgements. This study was supported by Aventis Pharma, Germany.

List of study investigators:

W. Thomas, Grevenbroich-Hemmerden; T. Ullmann, Saarbrücken; D. Langguth, Halle; U. Grimm, H. Edlich, Coswig; H. Lehrmann MD, Tabarz; M.-S. Do Dip, M. Hentschel, U. Kihm, Düsseldorf; H. Heyden, Oberhausen; S. Bäumer, Essen; H.-J. Braun, Darmstadt; M. Steinkohl, H.M. Noltenius, Bremen; W. Wülfing, Isernhagen; V. Kleint, Celle; M. Vothknecht, Schlangen; C. Scherner, Alsfeld; C. Feuerherdt, Stendal; I. Schwertz, Salzwedel; T.U. Blunk, Uelzen; S. Bluhm, Salzgitter (Lebenstedt); M. Schneider, Hövelhof; K. Kaczmarek, Markkleeberg; D. Kowalski, Watzendorf; S. Czihal, Aschersleben; A. Lange, Weischlitz; C.H..Weißkopf, Waren; B. Köhler, Radebeul; G. Beyer, Mücheln; D.W. Elfes, Hof; C. Höhne, Herzberg; A. Schroth, Oranienbaum; U. Mudra, Schmalkalden; G. Polivka, Sömmerda/Thüringen; K. Göthe, Nöbdenitz; W. Jerusel, Kitzscher; P. Striegler, R. Weichhardt, Leipzig; J.F. Langhans, Uttenreuth; A. Torka, Schönau am Königssee; M. Kaiser, Parsberg; M. Rohde, Tostedt; J.-M. Träder, Lübeck; H.-P. Huefnagels, Nettersheim; A. Hirschner, Rheinbach; M. Halir, Worms; U. Hebell, Eisenberg-Steinborn; S. Katzenbach, Frankenthal; N. Reuter, Mainz-Marienborn; R. Lang-Schuller, Gilching; P. Weber, M. Moerler-Ulirsch, P. Kasper, Munich; I. Botchko-Steck, Giengen/Brenz; D. Eisele, Roggenburg; T. Schein, Hettstedt; S.T. Brundisch, Großörner; R. Czerwinski, Taucha; C. Folz, Wipfeld; R. Hißlinge, Chemnitz; H.A. Lüddeke, Lengede; G. Gebauer, Neubrunn; C. Müller, Ahrensburg; T. Miklik, Kiel; R. Lohrey, M. Claus, W. Strasburger, M. Golinske, Hamburg; K. Mann, Neuenburg; B. Stiegler, Sigmaringen; W. Salge, Friesenheim; K. Eckert, Geislingen; A. Lambregts, Dreis; J. Pohl, Aschberg; G. Rüter, Benningen; I. Scheinhütte, Eberdingen; W. Staub, Aalen; J. Ascherl, Fellbach-Schniden; K. Kaltefleiter-Jürgens, Ennigerloh; T. Uhländer, Recklinghausen; H. Hoffmann, Mendig; A. Görg, Höhr-Grenzhausen; K. Hofer, Schleswig; B. Houben, G. Reifferscheidt-Gundermann, Cologne; P. Mummel, Herdecke; P.M. Fleischer, Bottrop; R. Michels, W. Hübner, Leverkusen; H. Jürgen, R. Bartels, Breuberg/Neustadt; J.D. Glaser, LeimenSt. Ilgen; R. Galjas, Neusäß; H. Deesz, Merzig-Schwemlingen; G. Zimper, Kirkel-Altstadt; B. Schneider, Hütschenhausen; W. Machold, Wolnzach; B. Peters, Langerwehe; G. Penteker, Hemmoor; H. Opitz, Frontenhausen; K. Ritter, Aschaffenburg; D. Schumacher, Stelle/Alshausen; A. Greb, Neustadt (Schneeren); K. Ohnesorge, Braunschweig (Wenden); F. Mihm-Speiser, Asslar; M. Karges, Hofbieber; B. Küneth, Neumarkt; M. Fröhlich, Durach; R. Binder, Bruckmühl; G. Rass, Ingolstadt; A. Jung-Casper, Ertingen; J. Sahling, Seevetal; R. Hennecke, Winsen/Luhe; W. Ihl-Beste, Ober-Mörlen; G. Raab, Marktredwitz; H. Stern, Neuss; W. Bös, Bad Soden-Salmünster; A. Gilbert, Dahn; J. Keßel, Marl.

\section{References}

1. Tremble JM, Donaldson D (1999) Is continued weight gain inevitable in type 2 diabetes mellitus? J R Soc Health 119:235-239

2. Williams KV, Kelley DE (2000) Metabolic consequences of weight loss on glucose metabolism and insulin action in type 2 diabetes. Diabetes Obes Metab 2:121-129.

3. UK Prospective Diabetes Study (UKPDS) Group (1998) Intensive blood-glucose control with sulphonylureas or insulin compared with conventional treatment and risk of complications in patients with type 2 diabetes (UKPDS 33). Lancet 352:837-853. 
4. Scholz G, Schneider K, Knirsch W, Becker G (2001) Efficacy and tolerability of glimepiride in daily practice. Clin Drug Invest 21:597-604

5. Weitgasser R, Lechleitner M, Luger A, Klinger A (2003) Effects of glimepiride on HbA1c and body weight in Type 2 diabetes: results of a 1.5 year follow-up study. Diabetes Res Clin Pract 61:13-19

6. Müller G, Satoh Y, Geisen K (1995) Extrapancreatic effects of sulfonylureas - a comparison between glimepiride and conventional sulfonylureas. Diabetes Res and Clin Pract 28 [Suppl]:S115-S137

7. Müller G (2000) The molecular mechanism of the insulinmimetic/sensitizing activity of the antidiabetic sulfonylurea drug Amaryl. Molecular Medicine 6:907-933

8. Holstein A, Plaschke A, Hammer C, Egberts E-H (2003) Characteristics and time course of severe glimepirideversus glibenclamide-induced hypoglycaemia. Eur J Clin Pharmacol 59:91-97

9. Korytkowski M, Thomas A, Reid L, Tedesco MB, Gooding WE, Gerich J (2002) Glimepiride improves both first and second phases of insulin secretion in type 2 diabetes. Diabetes Care 25:1607-1611

10. Overkamp D, Volk A, Maerker E, Heide PE, Wahl HG, Rett K, et al. (2002) Acute effect of glimepiride on insulinstimulated glucose metabolism in glucose-tolerant insulinresistant offspring of patients with type 2 diabetes. Diabetes Care 25:2065-2073

11. Sacks H, Chalmers TC, Smith H Jr (1982) Randomized versus historical controls for clinical trials. Am J Med 72:233-240

12. Kunz R, Oxman AD (1998) The unpredictability paradox: review of empirical comparisons of randomised and nonrandomised clinical trials. BMJ 317:1185-1190

13. Benson K, Hartz AJ (2000) A comparison of observational studies and randomized, controlled trials. N Engl J Med 342:1878-1886

14. Concato J, Shah N, Horwitz RI (2000) Randomized, controlled trials, observational studies, and the hierarchy of research designs. N Engl J Med 342:1887-1892
15. Horwitz RI, Viscoli CM, Clemens JD, Sadock RT (1990) Developing improved observational methods for evaluating therapeutic effectiveness. Am J Med 89:630-638

16. Rubin DB (1997) Estimating causal effects from large data sets using propensity scores. Ann Intern Med 127:757763

17. Schneider B (2001) Analysis of therapeutic efficacy in observational cohort studies. Cancer Chemother Pharmacol 47 [Suppl]:S35-37

18. Rosenbaum PR, Rubin DB (1983) The central role of the propensity score in observational studies for causal effects. Biometrika 70:41-55

19. Draeger K, Wernicke-Panten K, Lomp HJ, Schuler E, Rosskamp R (1996) Long-term treatment of type 2 diabetic patients with the new oral antidiabetic agent glimepiride (Amaryl): a double-blind comparison with glibenclamide. Horm Metab Res 28:419-425

20. Müller G, Hartz D, Punter J, Okonomopulos R, Kramer W (1994) Differential interaction of glimepiride and glibenclamide with the beta cell sulfonylurea receptor. I. Binding characteristics. Biochim Biophys Acta 1191: 267-277

21. Sigal RJ, El-Hashimy M, Martin BC, Soeldner JS, Krolewski AS, Warram JH (1997) Acute postchallenge hyperinsulinemia predicts weight gain: a prospective study. Diabetes 46:1025-1029

22. Kay JP, Alemzadeh R, Langley G, D'Angelo L, Smith P, Holshouser S (2001) Beneficial effects of metformin in normoglycemic morbidly obese adolescents. Metabolism 50:1457-1461

23. Rydberg T, Jonsson A, Roder M, Melander A (1994) Hypoglycemic activity of glyburide (glibenclamide) metabolites in humans. Diabetes Care 17:1026-1030

24. Badian M, Korn A, Lehr K-H, Malerczyk V, Waldhausl W (1996) Pharmacokinetics and pharmacodynamics of the hydroxymetabolite of glimepiride (Amaryl) after intravenous administration. Drug Metabol Drug Interact 13:69-85 